\title{
Research on Reliability Evaluation and Scheme Optimization of Main Connection Mode of Substation
}

\author{
WANG Ning*, LI Yan, YANG Hongwei, HU Yuan, WANG Suo \\ ${ }^{1}$ State Grid Hebei Economic Research Institute, Shijiazhuang, Hebei, 050000, China
}

\begin{abstract}
When designing the main wiring scheme of the substation, it is necessary to comprehensively consider the problems of dense power grid, high system stability and outstanding short-circuit current problems, and improve the reliability of power supply according to the actual situation of urban development. This design plan optimizes the main wiring form, and conducts optimization research from the three aspects of reliability, flexibility and economy. After technical and economic demonstrations, the optimal design form of the main wiring of the $220 \mathrm{kV}$ substation is determined, and it has good economic benefits. The main wiring scheme of $220 \mathrm{kV}$ substation with social benefits.
\end{abstract}

\section{Introduction}

Substation is a key component to ensure the safe and stable operation of the power system. The most important part of the power supply system is the primary system. The design of electrical main wiring is the core part of the primary design of the substation. Only a reasonable design of the main electrical wiring of the substation can ensure the reliability and flexibility of the entire power system. By analyzing the design content of the electrical main wiring of the substation and the design requirements of the electrical main wiring, the optimal design plan of the electrical main wiring will be find out, which will bring more help to the primary design work of the substation in the future.

\section{Principles of electrical main wiring design}

\subsection{Substation construction scale}

A substation is planned to install $4 \times 240$ MVA main transformers in the long term. There are 6 outlets for $220 \mathrm{kV}$ and 24 outlets for $110 \mathrm{kV}$. $220 \mathrm{kV}$ power distribution device is double-bus single section wiring, $110 \mathrm{kV}$ power distribution device is single bus four section wiring, and $10 \mathrm{kV}$ power distribution device is single bus ring 8 -section wiring. The qualifying line in this period was completed at one time. According to the characteristics of the project, the main wiring considers the design principle of combining the long-term and short-term to facilitate the transition of the expansion project as much as possible.

\subsection{Design principles of electrical main wiring}

The main wiring of the substation is an important part of the power system network structure, which directly affects the reliability and flexibility of operation, and has a decisive relationship with the selection of electrical equipment, the layout of power distribution devices, and the setting of relay protection, automatic devices and control methods.

The determination of the electrical main wiring needs to be combined with the comprehensive consideration of the position and role of the substation in the power grid, the environmental conditions of the site, the outgoing conditions, the selection of electrical equipment, the layout of power distribution devices, and the integration of equipment. Combined with the research results and construction concepts of smart substation design technology.

The following is a comprehensive technical and economic comparison of the main wiring, and an analysis of the impact of the optimized main wiring scheme on production safety, operation, and maintenance. After striving for optimization, the main wiring can not only meet the requirements of reliability, flexibility, and economy, but also integrate the actual project. Fully reflect the technical direction of the main wiring of the smart substation.

\section{Electrical main wiring scheme}

According to the development plan of the area where the project is located and the scale of the city, the main wiring schemes are compared from the double bus wiring method, the double bus single segment wiring method and the double bus double segment wiring method. 
The characteristic of double-bus wiring is that each element on the loop is connected to two sets of buses through a circuit breaker and two sets of isolating switches. The two sets of bus bars are then connected to each other through a bus tie breaker. In this wiring method, each component can be connected to any bus bar through a bus bar isolation switch.

When the number of incoming and outgoing circuits of the double-bus connection power distribution device is large, in order to increase the reliability of the system power supply and the flexibility of operation, a section circuit breaker can be added to one of the double buses to form a double-bus single section connection. Sectional circuit breakers can also be added to the two busbars to form double-busbar double-section wiring. The characteristic of single-segment wiring is that the power supply and load can be flexibly combined into a threesegment bus; the characteristic of double-bus doublesegment wiring is that the power supply can run on foursegment bus or two-segment double bus. The insulating cylinder is made of epoxy resin, and the bus bar is encapsulated with silicon rubber. This structure not only has good environmental adaptability, but also fundamentally solves the impact of SF6 gas expansion in high temperature areas. Therefore, it is especially suitable for applications in high temperature areas. The solid insulated ring network cabinet eliminates the pressure gas box components, avoids the problem of gas box deformation and deflation in high altitude areas, and is suitable for applications in plateau areas.

In the normal operation mode and the failure mode, this paper compares the power failure range and the reliability of the main transformer power supply, and analyzes the reliability and scope of application of the three main wiring forms of $220 \mathrm{kV}$ substations. Considering operational flexibility, scheduling flexibility and convenience of expansion, the different characteristics of the three methods are analyzed. At the same time, the three methods are compared economically to get the economic pros and cons of the main wiring. Finally, choose the $220 \mathrm{kV}$ substation electrical main wiring suitable for the construction of this project.

\subsection{Reliability comparison}

According to the final situation of the substation with 4 main transformers, the components are evenly distributed on each bus section.

In the double-bus connection mode, two transformers are connected to each bus bar, with $\mathrm{N} 1$ outgoing wires for Bus I and N2 outgoing wires for Bus II. In the double-bus single-segment connection mode, section I and section II are connected to two transformers respectively. In the double-bus double-section connection mode, each section of the bus is connected to a transformer, and there are N1, N2, N3 and N4 outgoing lines on the bus bars I, II, III and IV respectively. The three main wiring diagrams are shown in the figure.

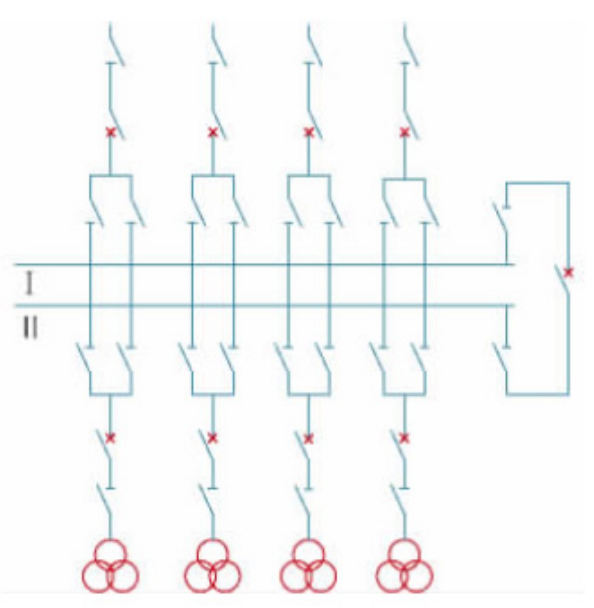

Figure 1 Double bus wiring diagram

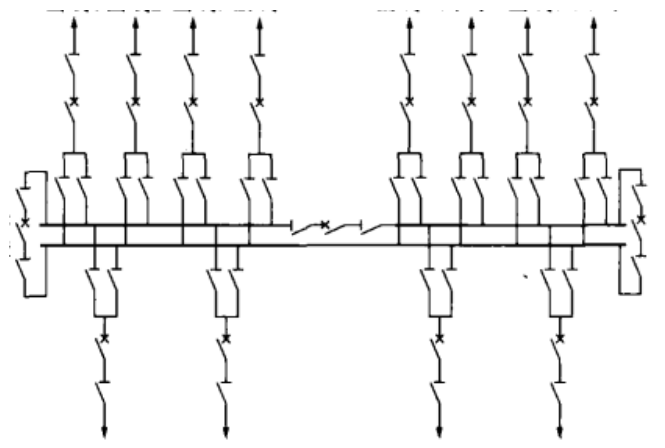

Figure 2 Schematic diagram of double bus single section wiring

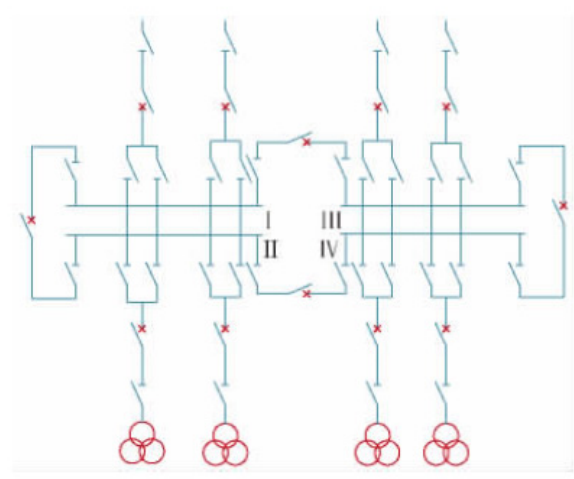

Figure 3 Schematic diagram of double busbar double segment wiring

The double-bus connection mode can alternately operate two sets of bus isolation switches, and one set of buses can be checked and repaired in turn without interrupting the power supply. When a group of busbars fails, the power supply can be quickly restored. However, if the circuit breaker of the outgoing line or the main transformer refuses to operate, the power outage range is $50 \%$. At the same time, it affects the operation of the two main transformers. In the case of $130 \%$ overload of the other two main transformers, $65 \%$ of the load can be supplied. When the bus tie breaker refuses to operate, the entire substation will be powered off. 
The double-bus single-segment connection can overcome the shortcomings of the double-bus connection of the whole station power outage, and the scope of the fault power outage is reduced to $66.7 \%$. When repairing the bus isolation switch of any component, the other two bus bars can maintain the double bus operation mode. When any circuit breaker is overhauled or another circuit breaker fails, more than 2 circuits need to be cut off.

In the double-bus double-section connection mode, the bus is divided into four sections. In this case, the bus can be operated in sections. The system configuration has a large degree of freedom, and two components can be completely connected to different bus bars. The reliability is higher than the other two wiring forms. When any incoming or outgoing circuit breaker fails or any segment of the bus fails, the power outage range is $1 / 4$ of the entire bus, and the load power supply guarantee rate is $97.5 \%$. When the section breaker or bus tie breaker fails, the power outage range does not exceed $50 \%$ of the entire bus, and the load power supply guarantee rate is 65 . When repairing the bus isolation switch of any one component, the other two buses can also maintain double bus operation. When any one circuit breaker is overhauled or another circuit breaker fails, more than two circuits need to be cut off.

\subsection{Flexibility comparison}

Operational flexibility: In the double-bus wiring mode, each power supply and outgoing line are connected to two bus bars. The outgoing lines can be arbitrarily allocated to a certain group of buses according to the actual situation. Bus maintenance and troubleshooting are more convenient. In addition to the flexibility of double-bus wiring, the double-bus single-segment wiring method can also meet the requirements of $220 \mathrm{kV}$ bus short-circuit current and system split operation. The double busbar double segment wiring method divides the two busbars into four sections. Each power supply and outgoing wire are connected to two bus sections respectively. This wiring mode can meet the needs of substation operation in separate rows. It is more flexible in bus maintenance and troubleshooting, which can effectively guarantee load supply.

In terms of scheduling flexibility: Take the doubleloop chain structure as an example. There are three $220 \mathrm{kV}$ substations on the standard wiring of the doubleloop chain structure. The substation adopts double-bus main wiring and double-bus single-section wiring. In the normal operation mode, a $500 \mathrm{kV}$ substation on one side will operate with two $220 \mathrm{kV}$ stations. In the event of an accident, this mode of operation can be powered by a $500 \mathrm{kV}$ station on the other side of the line. If the substation located in the middle adopts the form of double busbar and double section, in addition to the above operation mode, the load of the same site can also be distributed to two power supply areas to realize the operation mode of separate power supply.

Consider the situation of high urban load density and heavy load in some substations. If the substation located in the middle is a heavy load substation, then some
$500 \mathrm{kV}$ substations will have heavy load conditions. When the substation located in the middle adopts the main wiring form of double bus single section and double bus double section, it can flexibly distribute all or part of the load to different power supply areas according to different operation modes and power flow, which is beneficial to the safety of the power grid. Stable operation.

Due to the high load density in the city, $220 \mathrm{kV}$ substations are densely distributed. The control of shortcircuit current has become a difficult point in the power grid of mega cities. At present, the method of district power supply is adopted. Some $220 \mathrm{kV}$ substations in the same power supply area have short-circuit current exceeding the standard, if the bus splitting operation mode is adopted to limit the short-circuit current. The main wiring mode of the double busbar section can only adopt the form of horizontal splitting, and the power supply and the outgoing line are connected by a single busbar. If there is a failure, the related lines will face the risk of low voltage. The main wiring of double bus single section and double bus double section can adopt the form of longitudinal split. After the busbar is split, the two sides of the busbar are still connected with double busbars, which has higher reliability and flexibility in operation.

\subsection{Economic comparison}

The three main wiring methods are basically the same in terms of floor space and power loss. Its economy mainly depends on equipment investment.

Compared with the double busbar connection, the double-bus single-segment wiring method adds 1 segment interval and 2 sets of busbar protection, and the total investment increases 2.28 million; the double-bus double-segment main wiring method increases by 2 compared to the double busbar wiring method Sectional interval, 1 bus tie interval and 2 sets of bus protection devices, the total investment increased by 5.88 million yuan. Compared with the investment in a $220 \mathrm{kV}$ substation with a capacity of $4 \times 240 \mathrm{MV} \cdot \mathrm{A}$, it accounts for about $1.75 \%$ of the total investment.

\section{Scalability analysis}

The project will be put into operation in 2020, and the current scale is 2 sets of $220 \mathrm{kV}$ main transformers, and the final scale is 4 sets. There are 6 lines at the final stage of $220 \mathrm{k}, 24$ lines at the final stage of $110 \mathrm{kV}$, and 48 lines at the final stage of $10 \mathrm{kV}$. All the lines are completed at one time.

This design optimization scheme mainly considers the length of power outage and economic operation cost during the expansion transition. When the interval between incoming and outgoing lines is expanded, whether it is on the $220 \mathrm{kV}$ side or the $110 \mathrm{kV}$ side, a power outage of 3 to 5 days is required. It is used for testing, equipment standing, and installation. Important loads will inevitably be affected. In this design optimization plan, all outlet intervals are built at one 
time, and only the corresponding cable terminals need to be connected during expansion. The power outage time is greatly shortened, the amount of expansion and transition works is significantly reduced, and the indirect economic loss can be controlled to a minimum. The estimated power outage time can be shortened from 3 to 5 days to half a day. Meet the requirements of scalability design.

\section{Conclusion}

This optimization design study combines the planning requirements of specific projects, smart substation design requirements and basic conditions of smart equipment. Under the premise of satisfying safety and reliability, the main wiring optimization design plan is proposed. The main wiring form of $220 \mathrm{kV}$ power distribution device is double-bus single-section wiring, $110 \mathrm{kV}$ is single-bus four-section wiring, and $10 \mathrm{kV}$ is single-bus ring 8-section wiring.

This optimized design analyzes the impact of the optimized main wiring scheme on production safety, operation, overhaul and maintenance through a comprehensive comparison of technology and economy. After demonstration, the optimized main wiring scheme can not only meet the requirements of reliability, flexibility, and economy, but also integrate the actual engineering, reflect the technical direction of the main wiring of the smart substation, and meet the requirements of power grid planning and construction.

\section{References}

1. Gong Dingwen. Comparison and selection of electrical main wiring schemes for hydropower stations. J. Henan Water Resources and South-toNorth Water Diversion, 2020(03)

2. Li Yuansi. Analysis of the main electrical wiring design points and improvement methods of thermal power plants. J. Enterprise Technology Development, 2016(25)

3. Qiao Guan, Chen Zhendong. Analysis of the basic requirements and key factors of the main electrical wiring of the power system. J. China Equipment Engineering, 2017(04)

4. Liao Mangmang. Analysis of electrical main wiring diagram in power distribution technology. J. Shandong Industrial Technology, 2016(03)

5. Jiang Jiaohui. Discussion on the design of the main electrical wiring of the substation. J. Shandong Industrial Technology, 2016(22) 